\title{
Cell proliferation and DNA replication defects in a Drosophila MCM2 mutant
}

\author{
Jessica E. Treisman, ${ }^{1,3}$ Peter J. Follette, ${ }^{2,3}$ Patrick H. O'Farrell, ${ }^{2}$ and Gerald M. Rubin ${ }^{1}$ \\ ${ }^{1}$ Howard Hughes Medical Institute and Department of Molecular and Cell Biology, University of California, Berkeley, \\ California 94720; ${ }^{2}$ Department of Biochemistry and Biophysics, University of California, San Francisco, \\ California 94143-0448
}

\begin{abstract}
The yeast $M C M 2, M C M 3$, and $M C M 5 / C D C 46$ genes are required for DNA replication and have been proposed to act as factors that license the DNA for one and only one round of replication per cell cycle. We have identified a Drosophila gene, DmMCM2, that is highly homologous to MCM2. A P-element insertion into this gene, which prevents its transcription, inhibits proliferation of cells in the imaginal discs and central nervous system (CNS) and causes an apparent prolongation of $S$ phase in the embryonic and larval CNS. DmMCM2 is expressed in the embryo in a pattern corresponding to that of $S$-phase cells. These results suggest that DmMCM2 plays a role in the regulation of DNA replication analogous to that of its yeast counterpart.
\end{abstract}

[Key Words: Drosophila; cell cycle; DNA replication; MCM; replication origins]

Received April 27, 1995; revised version accepted June 8, 1995.

Eukaryotic DNA replication is coordinated with the cell cycle such that DNA is replicated only during S phase, and each origin of replication is used only once per cell cycle. Blow and Laskey (1988) proposed a model for replication control in which a positive licensing factor is required for the initiation of replication and is inactivated after the initiation event. This hypothetical factor cannot cross the nuclear envelope and so can enter the nucleus only when the envelope breaks down at mitosis. Evidence for such a licensing factor was provided by showing that G2 nuclei could re-replicate their DNA following permeabilization of the nuclear membranes in the presence of a Xenopus cytoplasmic extract (Blow and Laskey 1988; Coverley et al. 19931.

The Saccharomyces cerevisiae genes MCM2, MCM3, and MCM5/CDC46 were identified in a screen for mutations that decrease the stability of plasmids in proliferating cells (minichromosome maintenance) (Maine et al. 1984). These genes are all required for cell proliferation, and their protein products are homologous to one another, forming a gene family (Hennessey et al. 1991; Yan et al. 1991). Homologs of individual members of the MCM family have been found in Schizosaccharomyces pombe (Coxon et al. 1992; Miyake et al. 1993), Xenopus laevis (Buckbinder and Brown 1992; Coxon et al. 1992), and mammals (Hu et al. 1993). Their involvement in the initiation step of DNA replication has been indicated by a number of criteria (Gibson et al. 1990; Hennessy et al. 1990; Thömmes et al. 1992; Li and Herskowitz 1993), and mutations in MCM2 and MCM3 have been demonstrated in yeast to diminish the frequency of the firing of

${ }^{3}$ These authors contributed equally to this work. chromosomal origins of replication (Yan et al. 1993). In these experiments the decrease in the activity of a given origin sequence, or autonomously replicating sequence (ARS), depended on the particular MCM mutation examined, suggesting that individual members of this family interact differently with individual ARS sequences. The products of the yeast MCM genes display a cell cycledependent pattern of nuclear localization: They are present in the nucleus from the end of mitosis until the beginning of S phase (Hennessey et al. 1990; Yan et al. 1993). The mammalian MCM homolog Pl is present in the nucleus throughout interphase, but its intranuclear staining pattern, Triton X-100 extractability, and phosphorylation differ between $G_{1}$ and $G_{2}$ phases (Kimura et al. 1994). These changes in the localization or biochemical properties of the MCM gene products during the cell cycle correlate well with the distribution predicted for licensing factor activity, leading to the suggestion that the $M C M$ gene products are such factors (Hennessey et al. 1990; Tye 1994).

In multicellular organisms such as Drosophila, the nature of cell cycle regulation is subject to developmental control (Edgar and O'Farrell 1990; Smith and Orr-Weaver 1991; O'Farrell 1992; Edgar et al. 1994). The very rapid early embryonic cycles consist solely of $S$ and $M$ phases, and the $G_{1}$ and $G_{2}$ phases are introduced independently at different stages of embryonic development. Later, many cells enter endoreplicative cycles, in which DNA is replicated in multiple rounds of $S$ phase without intervening mitoses; these cycles ultimately give rise to the larval polytene chromosomes. Most larval growth occurs through such endoreplicative cell growth. In contrast, imaginal disc cells are set aside during embryogen- 
Treisman et al.

esis and proliferate extensively in larval and pupal stages, eventually generating the structures of the adult fly. A number of genes homologous to known cell cycle proteins, as well as novel proteins shown to function in the cell cycle, have been identified in Drosophila, and the analysis of their mutant phenotypes has often allowed insight into the nature of cell cycle regulation during development (Edgar and O'Farrell 1989; Lehner and O'Farrell 1989; Knoblich and Lehner 1993; Stern et al. 1993; Knoblich et al. 1994; Gönczy et al. 1994; Thomas et al. 1994). We report here the isolation of a Drosophila MCM2 homolog. A P-element insertion that prevents transcription of this gene affects DNA replication in the embryonic and larval central nervous system (CNS) and inhibits cell proliferation in the larval CNS and imaginal discs.

\section{Results and Discussion}

The $1(3) \mathrm{rL} 74$ mutation inhibits proliferation of imaginal disc and CNS cells

We have undertaken the characterization of a number of enhancer trap lines in which a P-element insertion leads to expression in the eye imaginal disc of a reporter gene and causes a recessive lethal phenotype. We have examined the effects of these insertions on eye development by using the FLP-FRT system, consisting of the yeast FLP recombinase and its target FRT sequence $\mathrm{Xu}$ and Rubin 1993), to induce homozygous mutant clones in the eye imaginal disc. Homozygous wild-type twin spot clones are generated concurrently and are usually of an equivalent size. However, clones homozygous for the 1(3)rL 74 insertion were always very small, even when their accompanying wild-type twin spots were quite large. Twin spots ranging in size from 5 to 55 ommatidia were observed in the absence of any mutant clone large enough to be externally visible (data not shown). On sectioning such eyes, small numbers of mutant photoreceptors and pigment cells, marked with white, were found to be present, often contributing to abnormal ommatidia (Fig. 1A). This phenotype suggested that the homozygous 1(3)rL74 insertion causes cell autonomous lethality or failure to proliferate.

The phenotype of homozygous mutant animals is consistent with an effect on cell proliferation. Homozygous I(3)rL74 mutants often survive through the three larval instars and pupariate but never develop into adults. These mutants often persist as third-instar larvae for several days and never pupariate as early as wild-type larvae. Dissection of homozygous mutant wandering third-instar larvae demonstrated that their CNSs were smaller than wild-type larval CNSs and that they lacked identifiable imaginal discs (Fig. 1D,E). When these mutant larvae were allowed to develop for very long periods [up to 10 days after egg laying (AEL) at $25^{\circ} \mathrm{C}$, their CNSs often approached the wild-type size and they occasionally formed small imaginal discs (data not shown). This suggests that some proliferation can occur during an extended larval period. In contrast to the proliferating cells

Figure 1. $1(3) r L 74$ inhibits proliferation of imaginal disc cells. $(A) \mathrm{A}$ section through an eye containing an $1(3)_{r} L 74$ mutant clone reveals a few unpigmented pigment cells (white asterisks) and photoreceptors (white arrow). Ommatidia with extra or missing photoreceptors are present in the region surrounding the clone. Polytene chromosomes from wild-type $(B)$ and homozygous $1(3)_{r} L 74$ (C) third-instar larval salivary glands were stained with orcein to reveal their banding pattern. The tip of the right arm of the second chromosome is shown in each case. There are no significant differences in the banding pattern in the $1(3) r L 74$ mutant, although the chromosomes are slightly smaller and show differences in the puffing pattern, which may be attributable to delayed development in the mutant larvae. Dissection of wild-type $(D)$ and homozygous $1(3)_{r} L 74(E)$ wandering third-instar larvae revealed an inhibition of cell proliferation in the CNS and imaginal discs of mutant larvae. Four leg discs (l) and an eye (e)-antennal (a) disc are visible in $D$, whereas no recognizable discs were present in the larva dissected in $E$. The homozygous mutant larvae were dissected 6 days AEL; by this time all of their heterozygous siblings had already pupariated. The overall body size, as well as the size of salivary gland nuclei, was similar between the mutants and the wild-type larvae dissected in this experiment (data not shown).

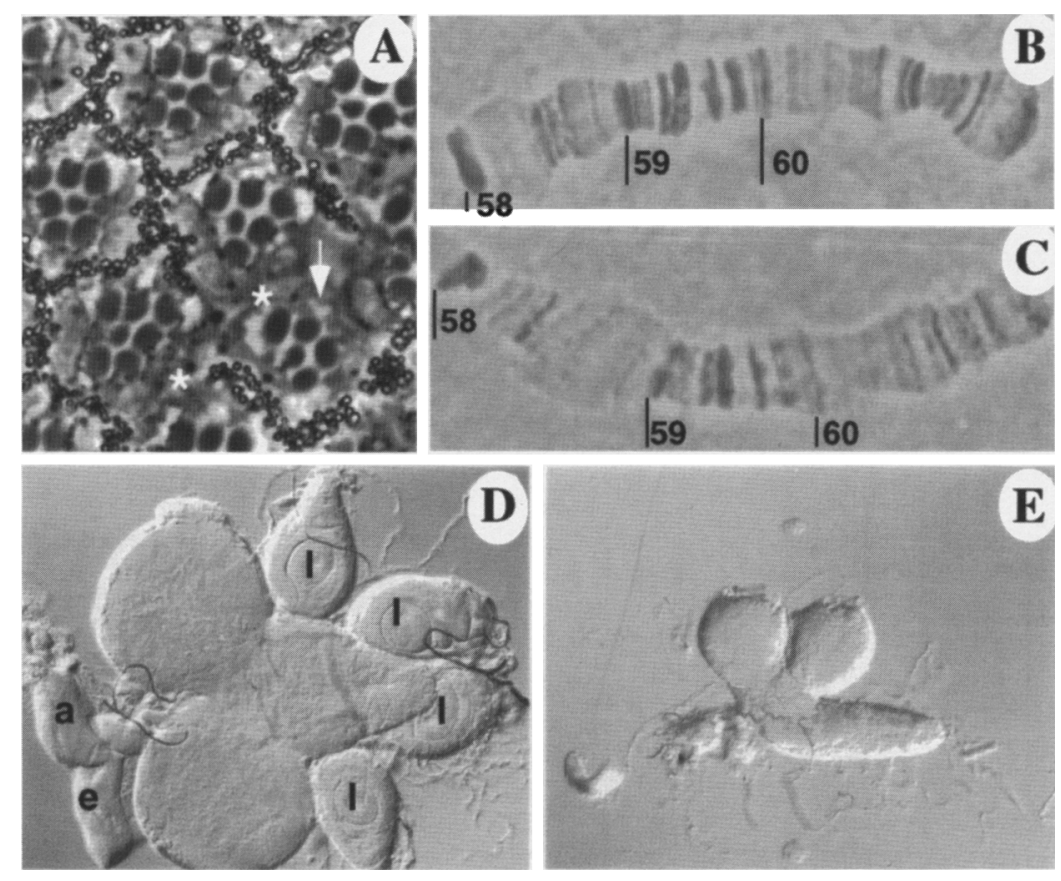


of the imaginal discs and CNS, the polytene cells of mutant salivary glands and gut appeared to grow normally (data not shown). Polytene chromosomes were still formed in the 1/3)rL74 salivary gland cells (Fig. 1C) and seemed to have replicated their DNA evenly, with no obvious constrictions or missing regions (cf. Fig. 1, B and C). However, the chromosomes were slightly smaller and more easily fragmented than normal.

\section{1/3|rL74 disrupts the DmMCM2 gene}

The $1(3) r L 74$ P element is located on the third chromosome, at 84F6-7; it was shown to be responsible for the lethal mutation, as its excision was sufficient to restore viability. Although a number of mutations causing reduced or absent imaginal discs have been described (Shearn and Garen 1974), none of them map to this position. DNA surrounding the $P$ element was cloned by plasmid rescue, and several classes of cDNAs in the region were isolated from an eye disc library. Their organization is shown in Figure 2A. The $5^{\prime}$ end of the longest member of class Tl is $6 \mathrm{bp}$ downstream of the site of P-element insertion and $151 \mathrm{bp}$ downstream of the closest TATAA box. Presumably, the true RNA start site is closer to this TATAA box and upstream of the P element. In situ hybridization to mutant embryos showed that no zygotic $\mathrm{Tl}$ transcript is present in $1(3) r L 74$ homozygotes (Fig. 3G, below), demonstrating that the P element prevents transcription of this coding sequence. The sequence of this CDNA was determined; the protein it encodes is highly homologous to $S$. cerevisiae MCM2, with $55 \%$ amino acid identity in a central 651-aminoacid region from amino acid 157 to 808 and $43 \%$ identity over the entire sequence (Fig. 2B). We therefore named this gene DmMCM2.

\section{The expression pattern of DmMCM2 correlates with S-phase cells}

In situ hybridization to wild-type embryos demonstrated that the DmMCM2 transcript is maternally contributed to the early embryo (Fig. 3A) and disappears at cellularization (Fig. 3B). Zygotic expression then begins uniformly at germ-band extension (Fig. 3C) and is subsequently restricted to a pattern that includes continuous expression in the CNS as well as transient expression in a number of other tissues, including the gut and Malpighian tubules (Fig. 3D-F). This expression pattern correlates well with the pattern of BrdU incorporation in the embryo and with the expression of other genes involved in DNA replication (Duronio and O'Farrell 1994).

\section{1(3)rL74 has a prolonged S-phase phenotype in the CNS}

In light of the demonstrated role of yeast MCM2 in DNA replication, we examined the pattern of incorporation of the nucleotide analog BrdU in DmMCM2 homozygous mutant embryos and larvae. Permeabilization and labeling of pre-stage 16 embryos collected from heterozygous parents failed to reveal a class of embryos with an abnormal pattern of replication (data not shown), presum-

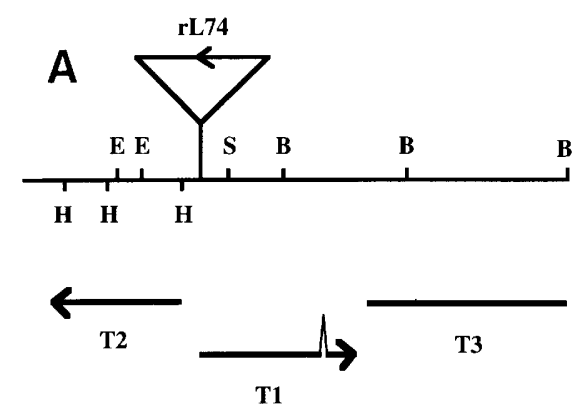

$\overline{1 \mathbf{k b}}$

B

DMMCM2 MDNPSSPPPNTPSDAAERRDLRAAMTSPVGDF MCM2 MSDNRRRRREEDDSDSENELPPSSPQQHFRGGMNPVSSPIGSPDMI DMMCM2 EPFENEDEILGDQTVRDEAEEEDGEELF GDNMENGYRPMPELDHYDFALLDDEDDFSEMS
MCM2 DMMCM2 QGDRFAAESEMRRRDRAAGIHRDDRDLGFGGSDDEDOVGPRAKRRAG-- - MCM2 LSERRIDAQLNERDRLLRNVAYIDDEDEEGEGAAQLDEMGLPVQRRRRRRYEDLENTD $\begin{array}{ll}\text { DMMCM2 } & \text {-EKAAVGEVEDTEMVES IENLEDTRGHSTKEWVSMLGPRTE[ANRF QSFLRTFVDERGAY } \\ \text { MCM2 DOLLSDIHIDPLREELTLESESNVEANSYEWITQPNVSRTIARELKSFLLEYTDETGRS }\end{array}$ DMMCM2 TVRDRIRRMCEQNMSSF VVSFT DLANKEHVLAYFLP EAFF QMLEIFDKVAKDMVLSI FPT
MCM2
VYYGARIRTLGEMNSESLEVNYRHLAESKAILALFLAKCPEEMLKIFDLVAMEATELHYPD

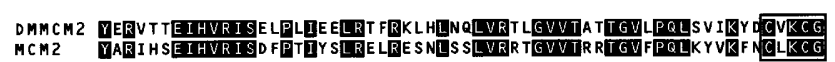

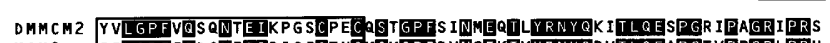
MCM2 SILGPFFDDSEETRISFGTNCKSKGPFRVIGEKTVYRNYGRVTLGEAPGTVPPGRLPAH DMMCM 2 KDVILLADLCDQCKPGDELEVTGIYTWNYDGSLETDQGFPVFATVLIANHVVVKDSK--MCM2 REVILLADLVDVSEPGEEVEVTGIYKWNYDGNLNAKNGFPVFATIIIEANS IKRREGNTAN

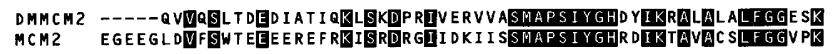
DMMCM2 NPGEKHKVRGD INLLI CGDPGTAKSQFLKYTEKVVPRAVFT TGGGASAVGLTAYVRRNPV MCM2 DVNPKHSIRGDINVLLLGDPGTAKSQILKYVEKTAHRAVFATGQGASAVGLTRSVRKHII $\begin{array}{ll}\text { DMMCM2 } & \text { SREWTLEAGALVLADQGVCLIDEFDKMNDQDRT S IHEAMEQQS IS ISKAGIVTSLQARCT } \\ \text { MCM2 } & \text { TKEWTLEGGALVLADKGVCLIDEFDKMNDQDRTS IHEAMEQQS IS ISKAG IVTTLQARCS }\end{array}$ DMMCM 2 VIIAAANPIGGRYDPSMTFS ENUNLLSEPILSRFDVLCUVKGE FEPMQDQQLAKFVVHSHMK MCM2 IIAAANPNGGRYNSTLPLAQNVSTTEPILSRFDILCVVRDLVGEEADERLATEVVDSHVR

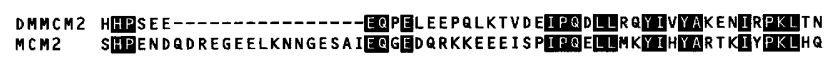
DMMCM 2 IDEDKI A KMYAQLRQESF ATGSLPI TVRHIESV IRM SEA HARMHLRENVMEADV S MAIRM MCM2 MEMDKVSRVYADLRRESISTGSFPITVRHLESI LAIAES FAKKRTLSEFUSSYELDRIATKV DMMCM2 MLESFIEAQRFSVMKKMRST FGKYLSFQKDHSELLFF ILRQLTLDQLAYIRCKDGPGATH
MCM2 DMMCM2 VEIMERDLIERAKQLDIVNLKPFYESDLFRTNGFSYPKRRIILQIVVDGNTA 887 MCM2 PLFFVE

Figure 2. $1(3) r L 74$ is inserted into the DmMCM2 gene. $(A)$ Organization of transcripts surrounding the $P$ element. The $5^{\prime}$ end of transcript T1, which encodes DmMCM2, is 6 bp from the $\mathrm{P}$ element, whereas the $5^{\prime}$ end of transcript $T 2$ is within $400 \mathrm{bp}$ of the $\mathrm{P}$ element. T1 contains one 58-bp intron; the intron-exon structure of $\mathrm{T} 2$ and $\mathrm{T} 3$ and the orientation of $\mathrm{T} 3$ have not been determined. $(B)$ Comparison of DmMCM2 and $S$. cerevisiae MCM2 sequences. Identical amino acids appear white on a black background. The zinc finger motif is boxed. The GenBank accession number for the DmMCM2 sequence is $\mathrm{L} 42762$.

ably because the levels of maternally supplied $D m M C M 2$ were sufficiently high to allow normal $\mathrm{S}$ phase during these stages. Labeling of CNSs from older homozygous mutant embryos and larvae, however, revealed a deviation from the normal pattern of $S$ phase.

In wild-type embryos, cells in the CNS incorporate BrdU until between stage 16 and 17 [14.5-16.5 hr AEL (Prokop and Technau 1991; P.J. Follette, unpubl.)], at 
Figure 3. Expression of DmMCM2 RNA in the embryo. All embryos except $B$ are oriented with anterior to the left and dorsal up. $(A)$ Uniform maternally contributed transcript is seen in a stage 4 embryo. $(B)$ Maternal transcript disappears during cellularization (stage 5). (C) Zygotic transcription is initially uniform at stage $8 .(D)$ In stage 11 , expression is mostly limited to the central and peripheral nervous system, with some underlying gut expression. $(E, F)$ Staining is clearly visible in the CNS and gut during stages 12 and 14. The pattern of gut staining seen here parallels both the pattern of $S$ phase and the expression of other $S$-phase genes during these stages (Duronio and O'Farrell 1994). (G) A stage 13 homozygous 1/3)rL74 mutant is clearly devoid of transcript throughout the embryo. A heterozygous control embryo is also visible here.

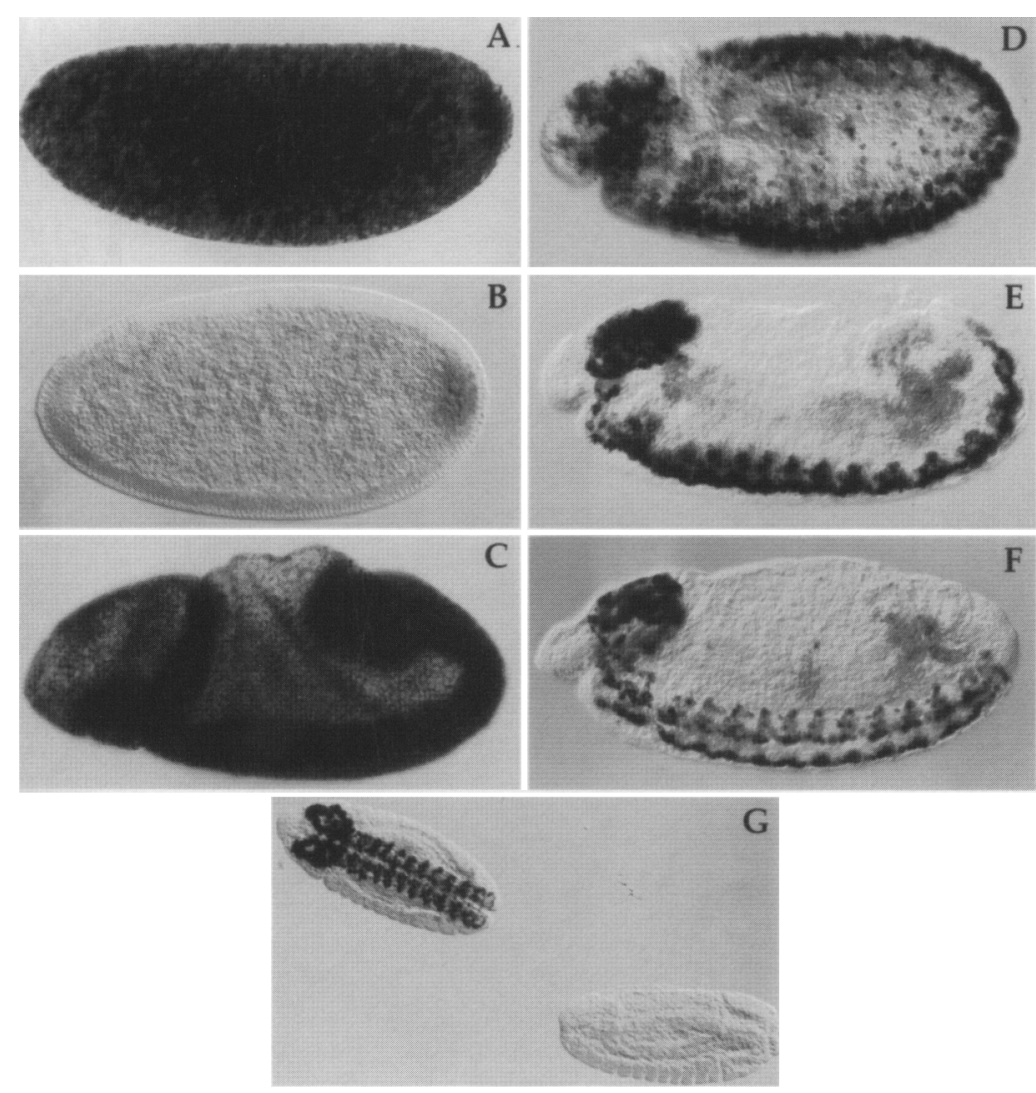

(Hartenstein et al. 1987). Alternative explanations for this phenotype, such as an increased level of cell proliferation or unscheduled entry into $S$ phase in the absence of gene product, do not easily account for either the gradual decline in the extent of labeling or the lack of any obvious increase in cell number or ploidy in later larvae (data not shown).

\section{Functions of the MCM gene family in DNA replication}

The licensing model posits a factor that is required for the establishment of functional replication origins (Blow and Laskey 1988). A limiting amount of licensing factor would thus be expected to reduce the number of functional, or licensed, origins, increasing the distance between them and consequently prolonging $\mathrm{S}$ phase (Fig. 5). In Drosophila, the pattern of BrdU incorporation in the CNS of homozygous DmMCM2 mutant embryos and larvae appears to reflect such an increase in the length of S phase. In yeast, as in Drosophila, there is considerable DNA replication even in the absence of individual MCM genes: Yeast cells with mutations in $M C M 2$ or $M C M 3$ arrest with an approximately $2 \mathrm{~N}$ DNA content (Yan et al. 1991). This implies that although each of these genes is essential for cell proliferation, some origins are still active in mutant cells. Presumably other MCM family members are sufficient for these origins to function.

The fact that MCM mutant yeast can replicate their DNA to a significant extent yet still cannot proliferate 

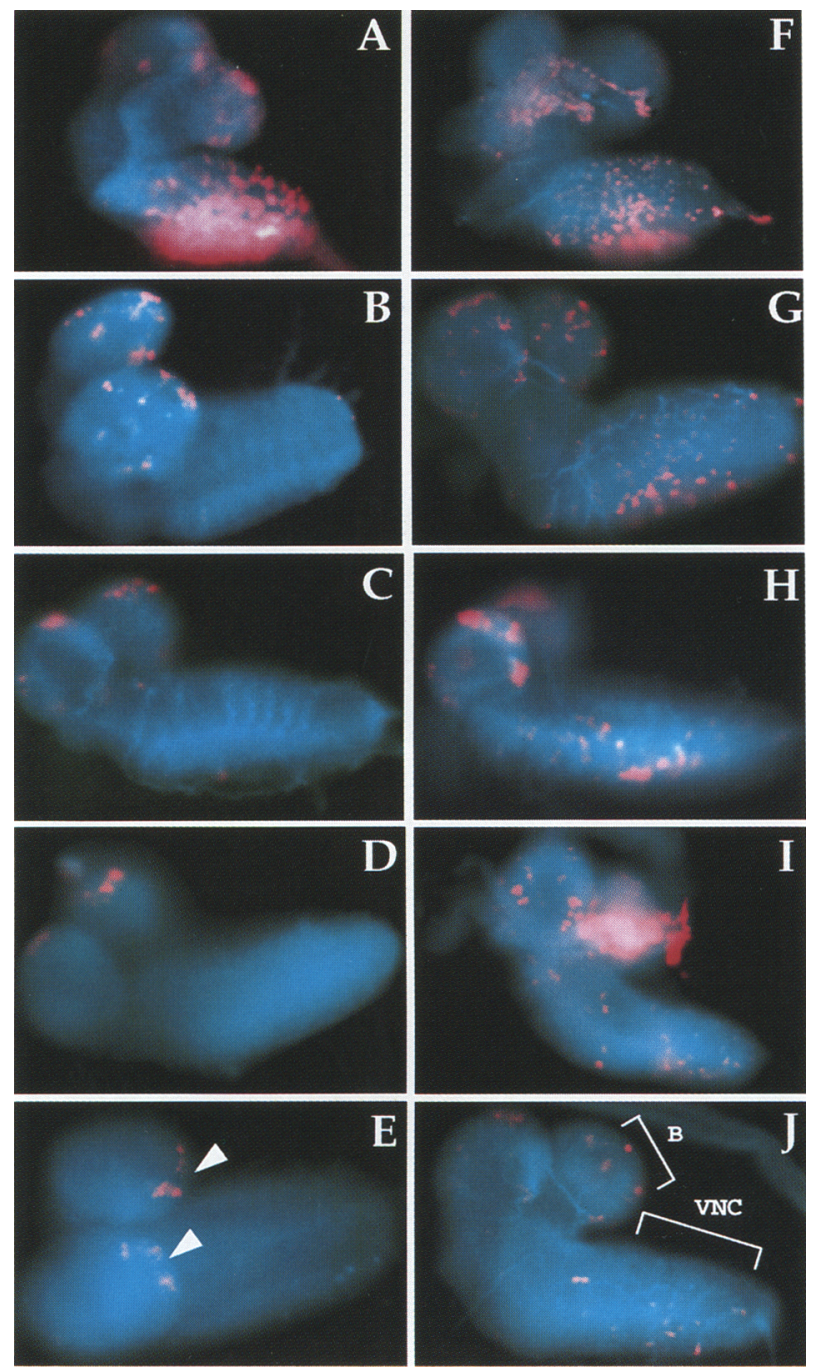

Figure 4. The pattern of BrdU incorporation is abnormal in the CNS of homozygous mutant embryos and larvae. Heterozygous controls $(A-D)$ and homozygous $(F-I)$ mutant embryos were injected at various times with BrdU and allowed to develop to hatching, or newly hatched heterozygous $(E)$ and homozygous $(J)$ larvae were fed BrdU for $6 \mathrm{hr}$. Cells labeled with BrdU are shown in red, and the overall shape of the CNS is colored blue. Anterior is left and dorsal up in all CNSs shown. The ages of the embryos at the time of injection were $12.5-13 \mathrm{hr}(A, F) ; 15-15.5 \mathrm{hr}(B, G)$; 17.5-18 $\mathrm{hr}(C, H) ; 19.5-20.25 \mathrm{hr}(D, I)$; and the larvae at the beginning of the 6 -hr feeding period were $\sim 0-2.25 \mathrm{hr}$ old $(E, J)$. Injection at $12.5-13 \mathrm{hr}$ AEL $(A, F)$ causes extensive labeling throughout the brain and ventral nerve cord (B and VNC in $/$ ) in both heterozygotes and homozygous $1(3)_{r} L 74$ mutants. By 15$15.5 \mathrm{hr}$ until $\sim 8 \mathrm{hr}$ after larval hatching $(B-E)$ very few cells other than those associated with the MBNbs /see arrowheads in $E)$ and LNbs incorporate BrdU. In contrast, homozygous embryos and larvae at these stages $(G-I)$ continue to incorporate BrdU, although the number of labeled cells decreases with advancing age. In $F, I$ small fragments of non-CNS tissue are partially obscuring the brain.

implies that unaffected origins cannot completely compensate for those that are affected. In mitotic cells, an incomplete $\mathrm{S}$ phase would prevent passage through mi- tosis and thereby prevent cell proliferation. The effect on endoreplicative cycles should be less severe, however, as even in normal Drosophila endocycles not all regions of the genome are replicated to the same extent (Lifschytz 1983; Spierer and Spierer 1984; Lamb and Laird 1987). In addition, the effects of prolonging $S$ phase may differ for mitotic and endoreplicative cells. Because proliferating cells must complete $S$ phase before they can enter mitosis, the length of $S$ phase limits the rate at which proliferation can occur; a substantially lengthened $S$ phase would thus severely inhibit the growth rate of mitotic cells. In endoreplicating cells, however, it may be possible for origins to refire before the previous $S$ phase has been completed, creating an overlap between successive $S$ phases. Although this would cause an increase in the number of replication forks within a given replicon, the overall rate of chromosomal replication might not be affected. Both S-phase prolongation and the prevention of mitosis by incomplete DNA replication may explain why in DmMCM2 mutants cell proliferation in the CNS and imaginal discs is inhibited, yet endoreplicative cells in the gut and salivary glands are able to grow. According to these explanations, MCM function would be required equally for DNA replication in diploid and endoreplicative cells, but the consequence of a defect in function would be much greater in diploid cells.

An alternative possibility is that the $M C M$ genes, though expressed in endoreplicative cells, may not be required for replication in these cells. This possibility is intriguing because it would suggest that multiple rounds of $S$ phase without mitosis might be achieved by a cell cycle modification that bypasses a requirement for $M C M$ function. This would imply that these genes may be acting to regulate the initiation of DNA replication in mitotic cells rather than being directly involved in the enzymology of initiation of replication in all S-phase cells.

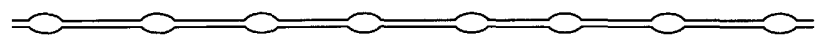

wild type $S$ phase

$D m M C M 2$ mutant S phase

Figure 5. The apparent increase in the length of $S$ phase in DmMCM2 mutant CNSs can be explained by a reduced number of functional replication origins in mutant cells. BrdU is incorporated for at least $7 \mathrm{hr}$ longer in the homozygous mutant CNS than in the wild-type CNS, although this time period may include more than one cell cycle considering the presence of small clusters of labeled cells. Assuming a rate of fork movement of $2.6 \mathrm{~kb} / \mathrm{min}$ (Blumenthal et al. 1973) and a replicon size of 10.6 $\mathrm{kb}$ (as seen in cycle 14; McKnight and Miller 1977), a very large number of replication origins must be eliminated to achieve such an increase. This could occur through the elimination of many individual origins, or of entire clusters of origins; the existence of clustered origins in some Drosophila cells has been deduced from an examination of the rate of fork movement, inter-origin spacing, and overall length of S phase (Blumenthal et al. 1973). 
We have not been able to distinguish these two possibilities by examining the structure of mutant polytene chromosomes. There do not seem to be any cytologically visible regions that absolutely require DmMCM2 function for their polytenization. However, the chromosomes are more fragile in the absence of DmMCM2, suggesting that the resistance to DNA breakage may be lowered by either small unreplicated gaps, perhaps at random positions, or an increase in the number of replication forks. Careful examination of replication in $\mathrm{mu}-$ tant endoreplicative cells will allow us to address this issue further.

Several other members of the MCM family have been found in Drosophila (T.T. Su and P.H. O'Farrell; G. Feger, H. Vaessin, T.T. Su, E. Wolff, L.Y. Jan, and Y.N. Jan; both in prep.). Reduction of the products of two of these genes by antibody injection (T.T. Su and P.H. O'Farrell, in prep.) or mutation (G. Feger, H. Vaessin, T.T. Su, E. Wolff, L.Y. Jan, and Y.N. Jan, in prep.) also affects DNA replication. The pattern of transcription appears essentially identical for all five of the genes in the family tested thus far (P.J. Follette, unpubl.; G. Feger, H. Vaessin, T.T. Su, E. Wolff, L.Y. Jan, and Y.N. Jan, in prep). Several of their protein products, including $D m M C M 2$, have been shown to be present in the nucleus throughout interphase, suggesting that they resemble the mammalian protein $\mathrm{Pl}$ rather than the yeast proteins (T.T. Su and P.H. O'Farrell, in prep.). Analysis of mutations in additional members of this family may help illuminate each of their unique roles in the control of $\mathrm{S}$ phase in Drosophila.

\section{Materials and methods}

\section{Clonal analysis}

Clones were generated by a 1 -hr heat shock at $38^{\circ} \mathrm{C}$ in firstinstar larvae using the FLP-FRT system (Xu and Rubin 1993). For twin spot analysis, the $\mathrm{P}\left[\right.$ mini- $\left.\mathrm{w}^{+}, h s-\mathrm{Nmyc}\right] 67 \mathrm{~B}$ marker was used (Xu and Rubin 1993). Adult eyes were fixed and sectioned as described (Tomlinson and Ready 1987).

\section{Larval growth conditions}

The 1(3)rL74 mutation was balanced with a yellow-marked TM6 chromosome, allowing the identification of homozygous mutant larvae. For analysis of the CNS and imaginal discs, homozygous mutants were identified as first-instar larvae, transferred to yeast paste on a grape juice agar plate, and allowed to develop in a humidified $25^{\circ} \mathrm{C}$ incubator. For polytene chromosome analysis, homozygous mutants were identified as wandering third-instar larvae and dissected. Wild-type controls were of the Sevelin strain.

\section{BrdU labeling}

Embryos were dechorionated in 50\% bleach, injected with 15 $\mathrm{mM} \mathrm{BrdU}$ in $200 \mathrm{~mm} \mathrm{KCl}$, and allowed to develop under oil until hatching, or larvae were fed yeast paste made up with a solution of $1 \mathrm{mg} / \mathrm{ml}$ of BrdU. Larvae were transected in $0.7 \% \mathrm{NaCl}$ and fixed for $1 \mathrm{hr}$ in $7 \%$ formaldehyde. They were then stained for BrdU incorporation essentially according to Truman and Bate (1987), except that rhodamine-conjugated secondary antibodies were used. The larvae were stained with the DNA-binding dye Hoechst 33258 and mounted for microscopy in Fluoromount G (Fisher).
The rhodamine and Hoechst images were captured separately using a charge-coupled device (CCD) camera, artificially labeled red (rhodamine) and blue (Hoechst), and merged using the ISEE program (Inovision) on a Silicon Graphics work station. Because of the acid treatment used to expose the BrdU for staining, the Hoechst acted only as a general dye to illuminate the overall shape of the CNS.

\section{Molecular biology}

DNA surrounding the 1(3)rL74 P-element was isolated by plasmid rescue (Mlodzik et al. 1990) and used to probe a cosmid library (Tamkun et al. 1992). DNA analysis was performed by standard procedures (Sambrook et al. 1989). cDNAs were isolated from a $\lambda g t 10$ third-instar-eye-antennal disc library (constructed by Alan Cowman, Walter and Eliza Institute, Victoria, Australia) and those corresponding to $\mathrm{Tl}$ were subcloned into pBluescript(II)SK + (Stratagene) and were sequenced on both strands using an Automated Laser Fluorescent DNA sequencer (Pharmacia). Sequences were analyzed using Staden software, and homology searches and alignments were done using the FASTA and BLASTP programs.

\section{In situ hybridization}

In situ hybridization to embryos was performed using digoxigenin-labeled RNA probes according to the method of Tautz and Pfeifle (1989) as modified by Duronio and O'Farrell (1994), except that the proteinase K step was omitted. The sense strand control showed no hybridization to embryos.

\section{Acknowledgments}

We are grateful to Todd Laverty for the polytene chromosome squashes shown in Figure 1 and for chromosome in situ hybridization, and to Noah Solomon for oligonucleotide synthesis. We thank Linda Higgins and Georg Feger for fly stocks. The manuscript was improved by the critical comments of Tom Neufeld. We also thank the members of the O'Farrell laboratory for discussion, especially Tin Tin Su and Bob Duronio. We are grateful to Georg Feger and Yuh Nung Jan for sharing unpublished results. J.E.T. was supported by a Jane Coffin Childs Memorial Fund postdoctoral fellowship. G.M.R. is a Howard Hughes Medical Institute investigator. P.J.F. was supported by a National Science Foundation Graduate Research fellowship. This work was supported in part by National Institutes of Health (NIH) grant GM33135 to G.M.R. and by NIH grants to P.H.O.

The publication costs of this article were defrayed in part by payment of page charges. This article must therefore be hereby marked "advertisement" in accordance with 18 USC section 1734 solely to indicate this fact.

\section{References}

Blow, J.J. and R.A. Laskey. 1988. A role for the nuclear envelope in controlling DNA replication within the cell cycle. Nature 332: 546-548.

Blumenthal, A.B., H.J. Kriegstein, and D.S. Hogness. 1973. The units of DNA replication in Drosophila melanogaster chromosomes. Cold Spring Harbor Symp. Quant. Biol. 38: 205223.

Buckbinder, L. and D. Brown. 1992. Thyroid hormone-induced gene expression changes in the developing frog limb. I. Biol. Chem. 72: 25786-25791.

Coverley, D., C.S. Downes, P. Romanowski, and R.A. Laskey. 1993. Reversible effects of nuclear membrane permeabilization on DNA replication: evidence for a positive licensing factor. J. Cell Biol. 122: 985-992.

Coxon, A., K. Maundrell, and S. Kearsey. 1992. Fission yeast $c d c 21+$ belongs to a family of proteins involved in an early 
step of chromosome replication. Nucleic Acids Res. 20: $5571-5577$.

Duronio, R.J. and P.H. O'Farrell. 1994. Developmental control of a G1-S transcriptional program in Drosophila. Development 120: 1503-1515.

Edgar, B.A. and P.H. O'Farrell. 1989. Genetic control of cell division patterns in the Drosophila embryo. Cell 57: 177187.

- 1990. The three postblastoderm cell cycles of Drosophila embryogenesis are regulated in G2 by string. Cell 62: 469-480.

Edgar, B.A., F. Sprenger, R.J. Duronio, P. Leopold, and P.H. O'Farrell. 1994. Distinct molecular mechanisms regulate cell cycle timing at successive stages of Drosophila embryogenesis. Genes \& Dev. 8: 440-452.

Gibson, S.I., R.T. Surosky, and B.K. Tye. 1990. The phenotype of the minichromosome mutant $\mathrm{mcm} 3$ is characteristic of mutants defective in DNA replication. Mol. Cell. Biol. 10: $5707-5720$.

Gönczy, P., B.J. Thomas, and S. DiNardo. 1994. roughex is a dose-dependent regulator of the second meiotic division during Drosophila spermatogenesis. Cell 77: 1015-1025.

Hartenstein, V., E. Rudloff, and J.A. Campos-Ortega. 1987. The pattern of proliferation of the neuroblasts in the wild-type embryo of Drosophila melanogaster. Wilhelm Roux's Arch. Dev. Biol. 196: 473-485.

Hennessey, K.M., C.D. Clark, and D. Botstein. 1990. Subcellular localization of yeast $c d c 46$ varies with the cell cycle. Genes \& Dev. 4: 2252-2263.

Hennessey, K.M., A. Lee, E. Chen, and D. Botstein. 1991. A group of interacting yeast DNA replication genes. Genes \& Dev. 4: 2252-2263.

$\mathrm{Hu}$, B., R. Burkhart, D. Schulte, C. Musahl, and R. Knippers. 1993. The Pl family: A new class of nuclear mamalian proteins related to the yeast MCM replication proteins. Nucleic Acids Res. 21: 5289-5293.

Ito, K. and Y. Hotta. 1992. Proliferation pattern of postembryonic neuroblasts in the brain of Drosophila melanogaster. Dev. Biol. 149: 134-148.

Kimura, H., N. Nozaki, and K. Sugimoto. 1994. DNA polymerase alpha associated protein $\mathrm{Pl}$, a murine homolog of yeast MCM3, changes its intranuclear distribution during the DNA synthetic period. EMBO I. 13: 4311-4320.

Knoblich, J.A. and C.F. Lehner. 1993. Synergistic action of Drosophila cyclins A and B during the G2-M transition. EMBO I. 12: 65-74.

Knoblich, J.A., K. Sauer, L. Jones, H. Richardson, R. Saint, and C.F. Lehner. 1994. Cyclin E controls S phase progression and its down-regulation during Drosophila embryogenesis is required for the arrest of cell proliferation. Cell 77: 107-120.

Lamb, M.M. and C.D. Laird. 1987. Three euchromatic DNA sequences under-replicated in polytene chromosomes of Drosophila are localized in constrictions and ectopic fibers. Chromosoma 95: 227-235.

Lehner, C.F. and P.H. O'Farrell. 1989. Expression and function of Drosophila cyclin A during embryonic cell cycle progression. Cell 56: 957-968.

Li, J.J. and I. Herskowitz. 1993. Isolation of ORC6, component of the yeast origin recognition complex by a one-hybrid system. Science 262: 1870-1874.

Lifschytz, E. 1983. Sequence replication and banding organization in the polytene chromosomes of Drosophila melanogaster. I. Mol. Biol. 164: 17-34.

Maine, G.T., P. Sinha, and B.K. Tye. 1984. Mutants of S. cerevisiae defective in the maintenance of minichromosomes. Genetics 106: 365-385.
McKnight, S.L. and O.L. Miller Jr. 1977. Electron microscopic analysis of chromatin replication in the cellular blastoderm Drosophila melanogaster embryo. Cell 12: 795-804.

Miyake, S., N. Okishio, I. Samejima, Y. Hiraoka, T. Toda, I. Saitoh, and M. Yanagida. 1993. Fission yeast genes ndal + and nda $4+$, mutations of which lead to S-phase block, chromatin alteration and $\mathrm{Ca}^{2+}$ suppression, are members of the CDC46/MCM2 family. Mol. Biol. Cell 4: 1003-1015.

Mlodzik, M., N.E. Baker, and G.M. Rubin. 1990. Isolation and expression of scabrous, a gene regulating neurogenesis in Drosophila. Genes \& Dev. 4: 1848-1861.

O'Farrell, P.H. 1992. Cell cycle control: Many ways to skin a cat. Trends Cell Biol. 2: 159-163.

Prokop, A. and G.M. Technau. 1991. The origin of postembryonic neuroblasts in the ventral nerve cord of Drosophila melanogaster. Development 111: 79-88.

Sambrook, J., E.F. Fritsch, and T. Maniatis. 1989. Molecular cloning: A laboratory manual, 2nd ed. Cold Spring Harbor Laboratory Press, Cold Spring Harbor, New York.

Shearn, A. and A. Garen. 1974. Genetic control of imaginal disc development in Drosophila. Proc. Natl. Acad. Sci. 71: 13931397.

Smith, A.V. and T.L. Orr-Weaver. 1991. The regulation of the cell cycle during Drosophila embryogenesis: The transition to polyteny. Development 112: 997-1008.

Spierer, A. and P. Spierer. 1984. Similar level of polyteny in bands and interbands of Drosophila giant chromosomes. $\mathrm{Na}$ ture 307: 176-178.

Stern, B., G. Ried, N.J. Clegg, T.A. Grigliatti, and C.F. Lehner. 1993. Genetic analysis of the Drosophila cdc2 homolog. Development 117: 219-232.

Tamkun, J.W., R. Deuring, M.P. Scott, M. Kissinger, A.M. Pattatucci, T.C. Kaufman, and J.A. Kennison. 1992. brahma: A regulator of Drosophila homeotic genes structurally related to the yeast transcriptional activator SNF2/SWI2. Cell 68: $561-572$.

Tautz, D. and C. Pfeifle. 1989. A non-radioactive in situ hybridization method for the localization of specific RNAs in Drosophila embryos reveals translational control of the segmentation gene hunchback. Chromosoma 98: 81-85.

Thomas, B.J., D.A. Gunning, J. Cho, and S.L. Zipursky. 1994. Cell cycle progression in the developing Drosophila eye: roughex encodes a novel protein required for the establishment of G1. Cell 77: 1003-1014.

Thömmes, P., R. Fett, B. Schray, R. Burkhart, M. Barnes, C. Kennedy, N.C. Brown, and R. Knippers. 1992. Properties of the nuclear P1 protein, a mammalian homologue of the yeast Mcm3 replication protein. Nucleic Acids Res. 20: 10691074.

Tomlinson, A. and D.F. Ready. 1987. Cell fate in the Drosophila ommatidium. Dev. Biol. 123: 264-275.

Truman, J.W. and M. Bate. 1987. Spatial and temporal patterns of neurogenesis in the central nervous system of Drosophila melanogaster. Dev. Biol. 125: 145-157.

Tye, B.K. 1994. The MCM2-3-5 proteins: are they replication licensing factors? Trends Cell Biol. 4: 160-166.

$\mathrm{Xu}$, T. and G.M. Rubin. 1993. Analysis of genetic mosaics in developing and adult Drosophila tissues. Development 117: 1223-1237.

Yan, H., S. Gibson, and B.K. Tye. 1991. MCM2 and MCM3, two proteins important for ARS activity, are related in structure and function. Genes \& Dev. 5: 944-957.

Yan, H., A.M. Merchant, and B.K. Tye. 1993. Cell cycle-regulated nuclear localization of MCM2 and MCM3, which are required for the initiation of DNA synthesis at chromosomal replication origins in yeast. Genes \& Dev. 7: 2149-2160. 


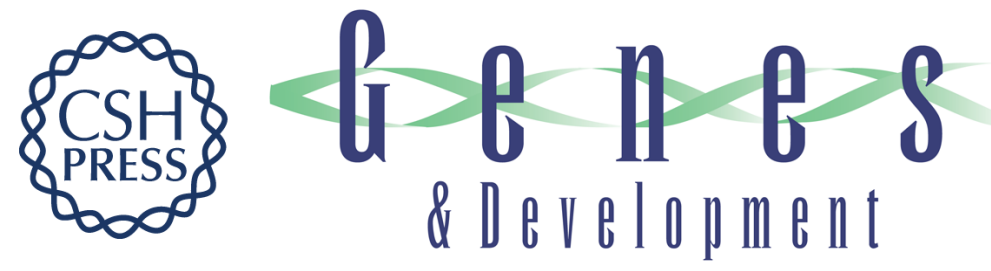

\section{Cell proliferation and DNA replication defects in a Drosophila MCM2 mutant.}

J E Treisman, P J Follette, P H O'Farrell, et al.

Genes Dev. 1995, 9:

Access the most recent version at doi:10.1101/gad.9.14.1709

References This article cites 43 articles, 16 of which can be accessed free at:

http://genesdev.cshlp.org/content/9/14/1709.full.html\#ref-list-1

License

Email Alerting

Service

Receive free email alerts when new articles cite this article - sign up in the box at the top right corner of the article or click here.

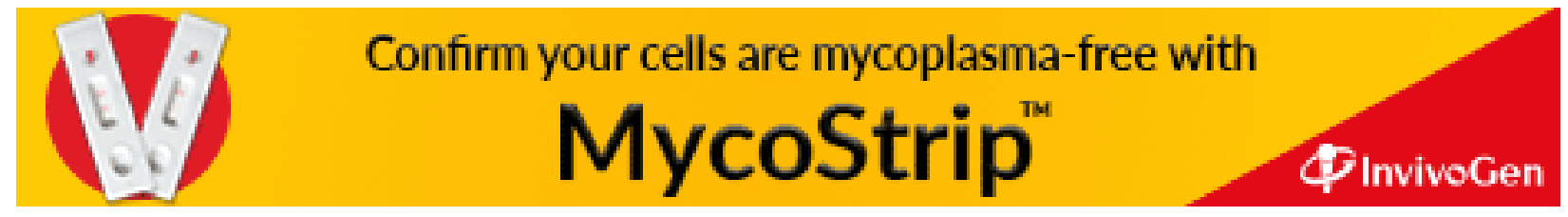

